\title{
Anodic Decomposition of Surface Films on High Voltage Spinel Surfaces - Density Function Theory and Experimental Study
}

\author{
Kevin Leung \\ Sandia National Laboratories, MS 1415, Albuquerque, \\ NM 87185, USA, E-mail: kleung@sandia.gov \\ Rosy and Malachi Noked \\ Department of Chemistry, Bar-Ilan University, Ramat Gan, 52900, Israel, \\ E-mail: rrosysharma@gmail.com, E-mail: malachinoked@biu.ac.il
}

(Dated: March 10, 2020)

\begin{abstract}
Oxidative decomposition of organic-solvent-based liquid electrolytes at cathode material interfaces has been identified as a main reason for rapid capacity fade in high-voltage lithium ion batteries. The evolution of "cathode electrolyte interphase" (CEI) films, partly or completely consisting of electrolyte decomposition products, has also recently been demonstrated to be correlated with battery cycling behavior at high potentials. Using Density Functional Theory (DFT) calculations, the hybrid PBE0 functional, and the (001) surfaces of spinel oxides as models, we examine these two interrelated processes. Consistent with previous calculations, ethylene carbonate (EC) solvent molecules are predicted to be readily oxidized on the $\mathrm{Li}_{x} \mathrm{Mn}_{2} \mathrm{O}_{4}$ (001) surface at modest operational voltages, forming adsorbed organic fragments. Further oxidative decompostion of such CEI fragments to release $\mathrm{CO}_{2}$ gas is however predicted to require higher voltages consistent with $\mathrm{Li}_{x} \mathrm{Ni}_{0.5} \mathrm{Mn}_{1.5} \mathrm{O}_{4}$ (LNMO) at smaller $x$ values. We argue that multi-step reactions, involving first formation of CEI films and then further oxidization of CEI at higher potentials, are most relevant to capacity fade. Mechanisms associated with dissolution or oxidation of native $\mathrm{Li}_{2} \mathrm{CO}_{3}$ films, which is removed before the electrolyte is in contact with oxide surfaces, are also explored.
\end{abstract}

\section{INTRODUCTION}

The use of high voltage cathode materials like $\mathrm{LiMn}_{1.5} \mathrm{Ni}_{0.5} \mathrm{O}_{4}$ spinel (LNMO) can contribute to significant increase in energy densities in lithium ion batteries $\underline{\underline{1}-\underline{\underline{4}}}$ Energy stored in batteries scale as $\Delta V^{2}$, where $\Delta V$ is the voltage difference between anode and cathode. LNMO can operate at $\sim 4.7-5.0 \mathrm{~V}$ vs. $\mathrm{Li}^{+} / \mathrm{Li}(\mathrm{s})$. High nickel content layered lithium nickel/manganese/cobalt (NMC) oxides also have the potential to expand the voltage window.

One obstacle facing the deployment of high voltage cathode materials is the apparent anodic instability of organic solvent molecules found in standard electrolytes (Fig 1), such as ethylene carbonate (EC) and dimethyl carbonate (DMC) $\underline{\underline{\underline{5}}} \mathrm{EC}$ and DMC oxidation has been proposed to lead to formation of thin cathode electrolyte interphase (CEI) films $\stackrel{1}{1} \underline{\underline{6}} \underline{-17}$ While the existence of CEI films on cathode surfaces has long been confirmed at modest voltages,$\frac{12-14,17}{2}$ questions remain about the origin of CEI species $\frac{18,19}{19}$ Although extensive spectroscopic and imaging studies have been conducted, the structure and function of CEI on cathode oxide material surfaces remain poorly understood. To complicate matters, transition metal ion dissolution from cathode oxide surfaces $\underline{20}$ and surface phase transformation of layered cathode oxides to form rock salts 21,22 can occur at the same time. Protective coating has been applied with some success $\stackrel{23-28}{-2}$ Electrolytes tailored for high voltages can also circumvent this problem,,$\frac{7,8,29}{2}$ often at the cost of higher electrolyte viscosity and material expense.

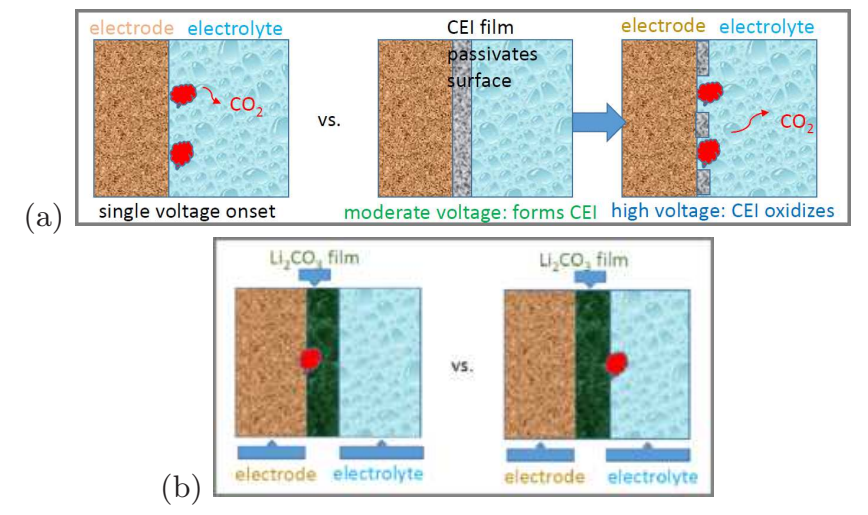

FIG. 1: Two main science questions addressed in this work. (a) One-step oxidative decomposition of organicsolvent-based electrolyte at high voltage vs. two- or multi-step degradation hypothesis, with the middle panel at intermediate voltages relevant to $<4.3 \mathrm{~V}$ conditions, and the right panel at high voltages relevant to LNMO. (b) Oxidation of $\mathrm{Li}_{2} \mathrm{CO}_{3}$ at its interfaces with LNMO vs. its reaction at the liquid electrolyte interface.

There is increasing experimental evidence that CEI components on cathode oxides are not static; they continue to evolve and/or become further oxidized as cycling proceeds to high voltages $\underline{15,17,30-35}$ This finding is not limited to the cathode side; evolution of SEI physical properties and chemical composition on anode surfaces has also been reported ${ }^{36-39}$ Recent differential and online electrochemical mass spectroscopy (DEMS, OEMS) measurements have proven extremely useful for corre- 
lating gas release with voltage changes $\underline{42-49}$ The onset of $\mathrm{CO}_{2}$ release from LNMO cells has been reported to be $\sim 4.6$ to $5.5 \mathrm{~V}$, except for open circuit and first-cycle contributions. $\mathrm{CO}_{2}$ release from layered NMC occurs at lower potentials and has been linked to reactive oxygen release. 43

Regarding theoretical modeling, anion-mediated EC oxidation has been predicted to occur in bulk solutions at about $5 \mathrm{~V}$ potentials $\stackrel{50,51}{\mathrm{EC}}$ is also predicted to undergo a one-step $\mathrm{CO}_{2}$ release reaction on LNMO (001) surfaces. ${ }^{52}$ However, there is substantial computational evidence that EC and DMC molecules already react with cathode oxide surfaces at more modest voltages,$\underline{53-63,63-65}$ especially on the surfaces of nickelfree manganese spinels $\left(\mathrm{LiMn}_{2} \mathrm{O}_{4}\right.$, or LMO) which do not normally operate beyond $\sim 4.3 \mathrm{~V}$. Strictly speaking, the predicted reactions are interfacial. Long range electron transfer into the liquid electrolyte is not yet predicted; instead direct contact between electrolyte and oxide surfaces is required $\underline{66}$ These predictions are inconsistent with the view that high voltages are needed to oxidize the electrolyte.

Based on these computational and experimental findings, we adopt an alternative view of high voltage cathode interfacial reactions which has already been suggested for oxidation on Pt surfaces ${ }^{16}$ (Fig. 17). (1) Solvent molecules in standard organic battery electrolyte first react with cathode oxide surfaces at modest voltages during charging. This occurs even on non-high-voltage materials like $\mathrm{Li}_{x} \mathrm{Mn}_{2} \mathrm{O}_{4}$. The oxidation generates adsorbed fragments which, to some extent, "passivates" surface reaction sites. (2) At higher voltages during charging, these CEI products become oxidized and are removed, releasing $\mathrm{CO}_{2}$ gas and leading to uncontrolled further electrolyte decomposition. We argue that the latter event is more responsible for rapid capacity fade (Fig. 14).

In this work, solvent decomposition products previously predicted to adsorb on LMO53,54 constitute our "CEI" model components. Until these species desorb, dissolves, and/or are themselves oxidized, they should sterically passivate cathode surfaces. We focus on these organic fragments, and omit inorganic CEI components like $\mathrm{LiF}$ and $\mathrm{Li}_{w} \mathrm{P}_{x} \mathrm{O}_{y} \mathrm{~F}_{z}$, related to $\mathrm{PF}_{6}^{-}$decomposition. Such inorganic species are present $12-14,40,41$ but neither release $\mathrm{CO}_{2}$ gas nor have been predicted to be oxidized at any reasonable voltages. Indeed, $\mathrm{PF}_{6}^{-}$decomposition products have been suggested to partially passivate LNMO 42

We apply Density Functional Theory calculations to illustrate the hypothesis (Fig. 1a). We adopt the (001) surfaces of LMO and high voltage spinel LNMO as model systems, and compute the thermodynamics and kinetics associated with degradation reactions. First we reexamine the initial EC oxidation steps ${ }^{53}$ using the hybrid PBE0 functional, $\frac{67}{6}$ which is generally more accurate for reaction barriers ${ }^{68,69}$ than the $\mathrm{DFT}+\mathrm{U}$ method ${ }^{70}$ widely used in the literature,,$\underset{53}{-65}$ but is far more computation- ally costly. Next we consider the further oxidation of these initial products on LNMO, and show that lower $\mathrm{Li}$ and higher $\mathrm{Ni}$ contents, which correspond to higher voltages, are needed to lower the reaction barriers sufficiently to activate further reactions that release $\mathrm{CO}_{2}$. Due to the computational cost, PBE0 is only used to examine the key reaction steps. One key finding is that $\mathrm{DFT}+\mathrm{U}$ can significantly underestimate reaction barriers compared to PBE0, yielding qualitative changes in mechanistic interpretations. Online electrochemical mass spectroscopy (OEMS) measurements are also conducted to support the theoretical results.

Other cathode interfacial evolution phenomena are related to the above discussions. First, the native $\mathrm{Li}_{2} \mathrm{CO}_{3}$ film covering most as-synthesized cathode oxide materials must somehow disappear or be ruptured before the elcetrolyte can react with them. It is widely accepted that native $\mathrm{Li}_{2} \mathrm{CO}_{3}$ films readily form on cathode oxide surfaces upon exposure to $\mathrm{CO}_{2}$ in air after

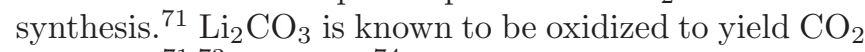

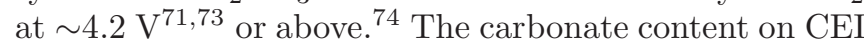
films on layered NMC has indeed been reported to fluctuate as cycling continues $\underline{30-33,73}$ Some studies suggest $\mathrm{Li}_{2} \mathrm{CO}_{3}$ dissolves due to reactions with $\mathrm{LiPF}_{6}$ degradation products like $\mathrm{HF} \stackrel{33}{3}$ However, Li-air battery studies, which do not involve $\mathrm{PF}_{6}^{-}$that generates $\mathrm{HF}$, also report $\mathrm{Li}_{2} \mathrm{CO}_{3}$ oxidation. ${ }^{73.74}$ Using the $\mathrm{DFT}+\mathrm{U}$ method and storage condition experiments, we perform exploratory studies to investigate whether oxidative reactions at the liquid electrolyte $/ \mathrm{Li}_{2} \mathrm{CO}_{3}$ interface occur more readily than at the $\mathrm{Li}_{2} \mathrm{CO}_{3} / \mathrm{LNMO}$ (001) interface (Fig. 10). Another interesting phenomenon is one version of "crosstalk" where SEI fragments diffuse from the anode to the cathode $\frac{18,19}{}$ and become oxidized $\stackrel{34}{ }$ Cross-talk products have variable structures, $\frac{19}{19}$ and they will not be considered herein. However, the principles and methods used in this work can also apply to study this phenomenon.

\section{METHODS}

We estimate mean reaction rates using the standard transition state theory rate equation

$$
1 / t_{\text {ave }}=k_{o} \exp \left(-\Delta E^{*} / k_{\mathrm{B}} T\right)
$$

where $\Delta E^{*}$ is the activation energy, $k_{o}=10^{12} / \mathrm{s}$ is a standard kinetic prefactor, and $k_{\mathrm{B}} T$ is the thermal energy at room temperature. Any step in the proposed reaction mechanisms is considered favorable if it is exothermic $(\Delta E<0)$ and if $t_{\text {ave }}$ is less than one hour - which trans-

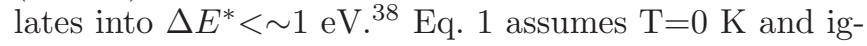
nores entropy which is small in most cases. As will be discussed, in a few relevant cases gas phase translational or vibrational entropic effects are added post-processing.

$\Delta E$ and $\Delta E^{*}$ are computed using $\mathrm{T}=0 \mathrm{~K}$ static ultrahigh vacuum (UHV) condition DFT calculations, conducted using periodically replicated simulation cells and 
the Vienna Atomic Simulation Package (VASP) version $5.3 \stackrel{75}{\underline{78}} \mathrm{~A} 400 \mathrm{eV}$ planewave energy cutoff and a $10^{-4} \mathrm{eV}$ convergence criterion are enforced. Antiferromagnetic ordering is imposed on $\mathrm{Li}_{x} \mathrm{Ni}_{0.5} \mathrm{Mn}_{1.5} \mathrm{O}_{4}$ and $\mathrm{Li}_{x} \mathrm{Mn}_{2} \mathrm{O}_{4}$.

Most DFT calculations herein apply the PerdewBurke-Ernzerhof (PBE) functional ${ }^{79}$ with the Hubbard $(\mathrm{DFT}+\mathrm{U})$ augmentation ${ }^{70}$ The $U$ and $J$ values associated with $\mathrm{DFT}+\mathrm{U}$ depend on the orbital projection scheme and DFT $+\mathrm{U}$ implementation details; here $(U-J)=4.84 \mathrm{eV}, 5.96$, and $3.30 \mathrm{eV}$ for $\mathrm{Mn}, \mathrm{Ni}$, and Co in accordance with the iterature $\underline{80} \underline{\underline{83}}$ Co-based materials are discussed only in the S.I. The PBE functional that underlies $\mathrm{DFT}+\mathrm{U}$ calculations tends to underestimate reaction barriers $\underline{68}$ because of localization errors $\underline{69}$ The hybrid PBE0 functional, generally considered more accurate than PBE for barriers,$\frac{68}{\underline{6}}$ is applied to key reaction steps as spot checks $\frac{67}{}$ Although fewer in number, these PBE0 calculations constitute the main results in this work. See the S.I. for rationale for choosing PBE0 over other hybrid functionals. In slab geometry DFT $+U$ calculations, the standard dipole correction is applied $\underline{84}$ It is found that this correction is on the order of meV, and it is omitted in PBE0 calculations.

Reaction barriers $\left(\Delta E^{*}\right)$ are computed using the climbing image nudged elastic band (NEB) method ${ }^{85}$ PBE0based NEB calculations require far more ionic steps than $\mathrm{DFT}+\mathrm{U}$ NEB. The reason is that, in the relevant oxidative reactions, protons and $e^{-}$are transferred simultaneously. The (spatial) radius of convergence associated with PBE0 NEB is small because the $e^{-}$being transfered is more localized than in DFT $+\mathrm{U}$ predictions. Therefore good initial guesses are needed to converge PBE0 NEB. Using DFT $+\mathrm{U}$ NEB configurations as guesses routinely fails to yield PBE0 barriers.

$2 \times 2 \times 2$ and $2 \times 2 \times 1$ Brillouin zone sampling schemes are adopted for LMO and LNMO bulk and surface unit cells. The DFT $+\mathrm{U}$ lattice constants for LMO and LNMO are predicted to be $8.40 \AA$ and $8.30 \AA$, respectively. PBE0 simulation cells are assumed to have the same cell dimensions. $1 \times 1$ surface cells are created by exposing (001) surfaces $\underline{81,86-88}$ The resulting slabs have $\mathrm{Li}_{n} \mathrm{Ni}_{4} \mathrm{Mn}_{16} \mathrm{O}_{40}$ or $\mathrm{Li}_{n} \mathrm{Mn}_{20} \mathrm{O}_{40}$ stoichiometries and no net dipole moment normal to the surface. The slight reduction in the $\mathrm{Ni} / \mathrm{Mn}$ ratio in our LNMO surface models, compared to the canonical $\mathrm{Li}_{x} \mathrm{Ni}_{0.5} \mathrm{Mn}_{1.5} \mathrm{O}_{4}$, is the result of using a fairly thin slab.

For the $1 \times 1$ (001) surface cells used, PBE0 is up to 100 times more costly than DFT $+\mathrm{U}$ for each ion step. Therein lies the advantage of using a small surface cell: the PBE0 functional can be applied more readily. Furthermore, the energies of all configurations with different $\mathrm{Ni}$ positions can be enumerated (at least when using the $\mathrm{DFT}+\mathrm{U}$ method). With $x \approx 1$ (i.e., under synthetic conditions), it is most energetically favorable to have one $\mathrm{Ni}$ on each surface and two $\mathrm{Ni}$ in the interior. To check system size effects, some DFT $+U$ calculations associated with the oxidation of EC fragments apply $1 \times 2$ surface supercells along with $2 \times 1 \times 1$ Brillouin sampling. These results, and justification for using a single adsorbed molecule at $\mathrm{T}=0 \mathrm{~K}$ to model anodic decomposition, are discussed in the S.I.

DFT + U-based vibrational frequency calculations are conducted to confirm that one of the configurations predicted to be a transition state (TST) indeed has only one unstable mode. The frozen phonon method is applied, with only the EC fragment allowed to move. In other words, oxide ions are assumed to be infinitely heavy. The vibrational contribution to the free energy difference between initial and transition states is estimated using a harmonic approximation,

$$
\begin{aligned}
\Delta \Delta A & =\Delta A_{\mathrm{TST}}-\Delta A_{\text {initial }} \\
\Delta A_{y} & =\sum_{i=1}^{n_{y}} \hbar \omega_{i}+k_{\mathrm{B}} T \log \left[1-\exp \left(-\hbar \omega_{i} / k_{\mathrm{B}} T\right)\right]
\end{aligned}
$$

where $y=$ initial or TST, $n_{y}=30$ or 29 in the two cases respectively, $\omega_{i}$ is the $i$ th vibrational frequency in the EC fragment, and $\hbar$ is Planck's constant.

Calculations on $\mathrm{Li}_{2} \mathrm{CO}_{3} / \mathrm{LNMO}$ interfaces apply $1 \times 3$ LNMO surface supercells along with $2 \times 1 \times 1$ Brillouin sampling. More details are provided in the S.I. Reactions between $\mathrm{Li}_{2} \mathrm{CO}_{3}$ films and EC molecules apply $2 \times 2 \times 1$ Brilloin zone zampling, $8.34 \times 10.02 \times 28 \AA^{3}$ simulation cells with $16 \mathrm{Li}_{2} \mathrm{CO}_{3}$ units, and $4 \mathrm{Li}$ removed from the surface.

The net electronic spin on each transition metal ion is examined to determine their charge states. $\mathrm{Mn}(\mathrm{II})$, $\mathrm{Mn}(\mathrm{III})$, and $\mathrm{Mn}(\mathrm{IV})$ are identified as $\mathrm{Mn}$ ions which exhibit net spins of $\sim 4.6, \sim 4.0$, and $\sim 3.3$ (all to within \pm 0.3 unit), as reported by the VASP code using its default PAW orbital settings. For added verification, the maximally localized Wannier orbitial method ${ }^{89}$ is applied to locate the center of all occupied orbitals within $0.3 \AA$ of each transition metal ion. By counting the number of occupied $d$-Wannier orbitals centered around each $\mathrm{Mn} / \mathrm{Ni}$, the charge state can be unambiguously assigned.

Regarding experiments: for making the composite electrodes, a uniform slurry was prepared by mixing $84 \%$ LNMO, 6\% CMC, and 10\% C65. The contents were thoroughly mixed using Thinky Mixer (ARV-310/ARV310LED) at $2000 \mathrm{rpm}$ and $40 \mathrm{kPa}$ for 3 minutes. The prepared slurry was then coated on a clean and polished $\mathrm{Al}$ foil using a doctor's blade adjusted for $60 \mu \mathrm{m}$ thickness. The coated sheet of aluminum foil was then heated at $100^{\circ} \mathrm{C}$ followed by rolling to ensure complete removal of trapped air or solvent. Vacuum dried electrodes with $12 \mathrm{~mm}$ diameter were used for the OEMS study.

For online electrochemical mass spectrometry, the OEMS cells were assembled using $\mathrm{Li}$ (14 $\mathrm{mm}$ diameter) as anode and LNMO composite electrode (12 mm diameter) as cathode. 2 poly-propylene separators $(29 \mathrm{~mm}$ diameter) were used between the two electrodes with 100 $\mu \mathrm{L}$ of LP30 (1M LiPF 6 in EC:DMC (1:1)) electrolyte. The cell was connected to OEMS (HPR-40, Hiden analytical) using a micro-capillary inlet with a sample rate 


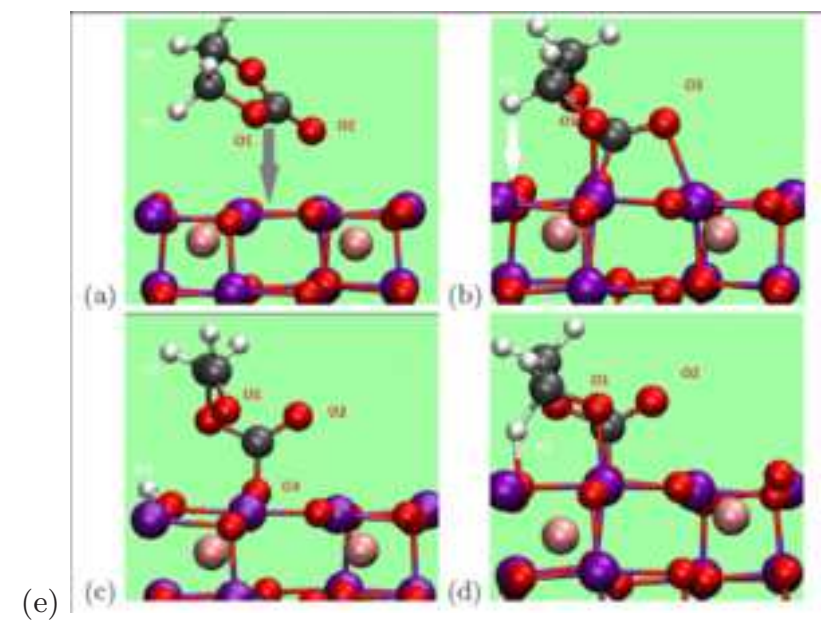

FIG. 2: PBE0-predicted configurations associated with EC decomposition on $\mathrm{Li}_{0.6} \mathrm{Mn}_{2} \mathrm{O}_{4}$ (001). (a) Intact EC; (b) partially decomposed but unoxidized EC fragment on $\mathrm{Li}_{0.6} \mathrm{Mn}_{2} \mathrm{O}_{4}$ (001); (c) oxidized EC fragment, $\Delta E=-1.91 \mathrm{eV}$ $(\mathrm{PBE} 0)$ relative to $(\mathrm{a})$; (d) transition state configuration $\left(\Delta E^{*}=+1.05 \mathrm{eV}, \mathrm{PBE} 0\right)$. Purple, pink, red, grey, and white spheres represent $\mathrm{Mn}, \mathrm{Li}, \mathrm{O}, \mathrm{C}$, and $\mathrm{H}$ atoms.

of $12 \mu \mathrm{L} / \mathrm{min}$. The galvanostatic charge/discharge was carried out using VSP- potentiostat (Bio-logic Science instruments) in a potential window of $3.5 \mathrm{~V}$ to $5.0 \mathrm{~V}$ at a rate of $\mathrm{C} / 10$. For the in-operando measurements of the evolved gases as a function of applied potential in the real-time frame, Mid mode was selected for $\mathrm{H}_{2}(\mathrm{~m} / \mathrm{z}$ $=2), \mathrm{CO}_{2}(\mathrm{~m} / \mathrm{z}=44)$, and $\mathrm{CO}$ and $\mathrm{C}_{2} \mathrm{H}_{4}(\mathrm{~m} / \mathrm{z}=28)$ gases.

\section{RESULTS AND DISCUSSIONS}

\section{A. Revisiting EC oxidation on LMO using DFT/PBE0}

Our previous computational work $, 53,54$ using the $\mathrm{DFT}+\mathrm{U}$ method, has shown that ethylene carbonate (EC) decomposition occurs readily on LMO (001) and (111). In particular, $40 \%$ charged LMO $\left(\mathrm{Li}_{0.6} \mathrm{Mn}_{2} \mathrm{O}_{4}\right)$ already oxidizes EC molecules on its (001) surface. The rate-determining, oxidative step releases $\Delta E=-$ $2.0 \mathrm{eV}$. The reaction barrier is predicted to be only $\Delta E^{*}=0.56 \mathrm{eV}$. According to Eq. 1] a reaction with this small $\Delta E^{*}$ occurs in millisecond time scales. Thus $\mathrm{Li}_{0.6} \mathrm{Mn}_{2} \mathrm{O}_{4}$, which should operate below $4.3 \mathrm{~V}$, is predicted to rapidly oxidize EC molecules. Higher voltages are not needed. The more accurate PBE0 mehthod has also been used to calculate $\Delta E .53$ However, $\mathrm{PBE0}$ reaction barriers $\left(\Delta E^{*}\right)$ have not been previously reported.

Fig. 2 describes new PBE0 $\Delta E^{*}$ predictions computed using the climbing image nudged elastic band method (NEB) $\stackrel{85}{=}$ First Fig. 2 depicts an intact EC on LMO (001) surface. Fig. 2b-d depict the initial, fi- nal, and barrier configurations associated with the ratedetermining oxidative step in the initial decomposition of EC molecules. Two $e^{-}$and a $\mathrm{H}^{+}$are transferred. $\Delta E$ is $-1.75 \mathrm{eV}$, which is only $0.25 \mathrm{eV}$ less exothermic than the $\mathrm{DFT}+\mathrm{U}$ value $\stackrel{53}{3}^{*}$ at the barrier top (Fig. 22 d) is found to be $1.05 \mathrm{eV}$ higher in energy than Fig. 1 b. This PBE0 $\Delta E^{*}$ is $0.49 \mathrm{eV}$ larger than $\mathrm{DFT}+\mathrm{U}$ value, in accordance with our expectation that PBE0 barriers are generally higher $\frac{68}{}$ This $\mathrm{PBE} 0 \Delta E^{*}$ value should be more accurate 68 $1.05 \mathrm{eV}$ is still consistent with a fast degradation reaction at room temperature, especially because the large zero point energy (ZPE) correction associated with proton motion has so far been neglected. ZPE contribution at $\mathrm{T}=300 \mathrm{~K}$ can be estimated using $\mathrm{DFT}+\mathrm{U}$ configurations, $\mathrm{DFT}+\mathrm{U}$ frozen phonon calculations which yield a single unstable vibrational mode at the transition state, and Eq. 2. We find that ZPE lowers $\Delta E^{*}$ (or more appropriately $\Delta G^{*}$, the free energy barrier) by $0.16 \mathrm{eV}$, to only $0.89 \mathrm{eV}$. This value is consistent with 4 reactions per hour (Eq. 1), well within battery time scales. We conclude that CEI products readily form on moderate voltage LMO (001).

Given the cost of PBE0 barrier calculations, we have not performed the same two $e^{-}$, one $\mathrm{H}^{+}$transfer calculation on LNMO (001). Since LNMO operates at higher voltages, and should yield more exothermic, faster reactions than corresponding ones on LMO, it is reasonable to assume the reactions of Fig. 2 also readily occur on LNMO (001) at the same Li-content.

\section{B. Further Oxidation on LMO and LNMO: DFT + U Predictions}

As discussed in Ref. 53, efforts to break other bonds in this partially oxidized EC fragment (Fig. 25) have yielded endothermic reactions. Hence this fragment has been assumed to persist during battery charging. However, a hitherto unexamined pathway proves favorable when using the DFT $+\mathrm{U}$ method. We stress, particularly to experimentalist readers, that more accurate $\mathrm{PBE} 0$ calculations presented in the next section suggest that $\mathrm{DFT}+\mathrm{U}$ overestimates reactivities. Nevertheless, it is useful to first report $\mathrm{DFT}+\mathrm{U}$ predictions.

The Fig. 3a configuration spontaneously emerges from Fig. 2r in finite temperature DFT+U-based molecular dynamics simulations, $\stackrel{53}{=}$ and involves lifting one $\mathrm{O}^{2-}$ anion out of the LMO surface. Static DFT $+\mathrm{U}$ calculations predict that it is $0.10 \mathrm{eV}$ more favorable than Fig. $2 \mathrm{r}$. We rotate this organic fragment so one of its H-atoms faces the oxide surface, remove one more Li to partially offset the implicit voltage decrease due to transfer of $e^{-}$ from EC to the oxide, and use the resulting configuration (Fig. 3b) as the re-starting point.

The next favorable step involves the transfer of a second $\mathrm{H}^{+}$and an $e^{-}$to the LMO surface (Fig. 3r). It is exothermic by $\Delta E=-0.46 \mathrm{eV}$ using the DFT $+\mathrm{U}$ method 


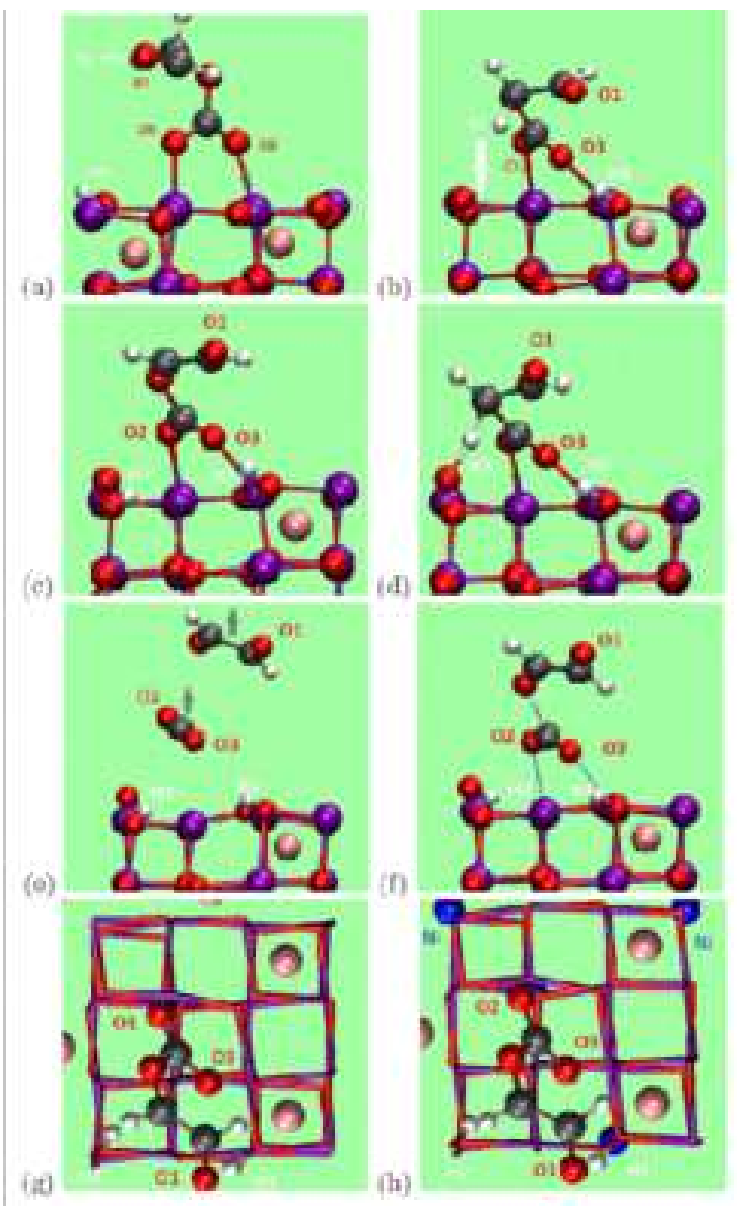

FIG. 3: LMO (001) configurations obtained using DFT+U calculations, but PBE0 configurations look superficially similar. (a) Surface $\mathrm{O}^{2-}$ anion coordinated to $\mathrm{C}$ moves out of the surface compared with Fig. 2r; (b) rotating panel (a) configuration and removing a $\mathrm{Li}$; (c) transferring a second $\mathrm{H}$ to surface; (d) $\mathrm{H}$ transfer transition state; (e) breaking C-O bond; (f) C-O cleavage transition state; (g) top view of panel (c); (h) same as (g) but for LNMO, with Ni depicted as blue spheres. Purple, pink, red, grey, and white spheres represent $\mathrm{Mn}, \mathrm{Li}$, $\mathrm{O}, \mathrm{C}$, and $\mathrm{H}$ atoms.

(Fig. 4a). The DFT+U transition state (Fig. [3 d) exhibits $\Delta E^{*}=+0.60 \mathrm{eV}$ relative to Fig. 3 $\mathrm{b}$; this value is similar to that in the proton transfer step (Fig. 2 $\mathrm{d}$ ) when using $\mathrm{DFT}+\mathrm{U}, \underline{53}$

Once this second hydrogen is transferred, the cleavage of the bond between the carbonyl carbon and an oxygen originally in the EC 5 -member ring becomes favorable by $\Delta E=-0.15 \mathrm{eV}$ relative to Fig. $3 \mathrm{k}$ according to DFT $+\mathrm{U}$. Breaking this bond leads to the release of both a $\mathrm{CO}_{2}$ and a glyoxal $\left(\mathrm{C}_{2} \mathrm{H}_{2} \mathrm{O}_{2}\right)$ molecule (Fig. 33). Without the prior $\mathrm{H}$-atom transfer step, $\mathrm{CO}_{2}$ elimination would have been accompanied by the release of a $\mathrm{CHOCH}_{2} \mathrm{O}$ radical, which is less energetically favorable, although a similar reaction appears favorable on LNMO 52 not LMO. It results in a 4-coordinated $\mathrm{Mn}$ (II) ion in Fig. 3.
The DFT+U-predicted barrier configuration (Fig. 3i) exhibits $\Delta E^{*}=0.46 \mathrm{eV}$ relative to Fig. 3r, and has a $1.95 \AA$ $\mathrm{C}-\mathrm{O}$ bond length. $\mathrm{C}_{2} \mathrm{H}_{2} \mathrm{O}_{2}$ is known to be a polymerizing agent. It is likely to react either with the oxide surface or other EC molecules in the solvent, and is not expected to be detected after cycling.

$\mathrm{DFT}+\mathrm{U}$ predicted EC fragment configurations on LNMO (001) are similar to those on LMO (001), and only one configuration is depicted (Fig. 3h). The only qualitative difference with LMO is that the 4-coordinated Mn in the final configuration on LNMO (Fig. Be for LMO) remains a $\mathrm{Mn}(\mathrm{III})$; a nickel ion is reduced instead of a $\mathrm{Mn}$ (III) following oxidation of the organic fragment. The final step $\Delta E^{*}=+0.32 \mathrm{eV}$ is lower than the corresponding $\mathrm{LMO}$ value (Fig. (4). Because the surface $\mathrm{Ni}$ introduces heterogeneity with respect to the EC binding site, we have translated the organic fragment in Fig. $3 \mathrm{~h}$ about the diagonal in the surface cell containing the surface transition metal ions, and find that the configuration depicted is within $0.03 \mathrm{eV}$ of the most stable among 8 choices we have considered.

The main problem with these $\mathrm{DFT}+\mathrm{U}$ results is that the predicted $\Delta E$ and $\Delta E^{*}$ for reactions on LNMO sur-

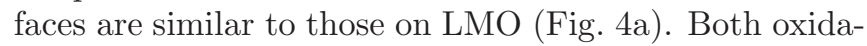
tion steps subsequent to the LNMO equivalent of Fig. 3 r are exothermic, and the average reaction times are much less than one hour. With all adsorbed organic fragments removed from their surfaces, LMO and LNMO should continuously react with solvent molecules and evolve $\mathrm{CO}_{2}$ at LMO operating potentials $(<4.3 \mathrm{~V})$. Experimentally, $\mathrm{CO}_{2}$ release is observed with LNMO at high voltage, but not with LMO at lower voltages after the first cycle $\underline{\underline{42}} \underline{\underline{49}}$ $\mathrm{DFT}+\mathrm{U}$ fails to distinguish LMO spinel and high-voltage LNMO spinel. Doubling the size the the simulation cell and adding more EC molecular fragments does not resolve this discrepancy between modeling and experiments (S.I.). The absence of molecular fragments on the cathode oxide at intermdediate voltages also seems inconsistent with two apparent $\mathrm{CO}_{2}$ onset potentails ${ }^{42}$ (see Sec. IIID below).

\section{Further Oxidation on LMO and LNMO: PBEO Predictions}

The PBE0 method is next applied to key reaction steps to distinguish LNMO from LMO. The PBE0-predicted configurations are qualitatively similar to those in Fig. 3 , and are depicted only in a few cases. But the energetics are substantially different (Fig. 4b).

First we revisit the transition between configurations Fig. 2r and Fig. 3a, which does not involve electron transfer. At this $\mathrm{Li}_{0.6} \mathrm{Mn}_{2} \mathrm{O}_{4}$ stoichiometry, DFT $+\mathrm{U}$ predicts $\Delta E=-0.10 \mathrm{eV}$. In contrast, the PBE0 functional predicts that $\Delta E=+0.16 \mathrm{eV}$. The PBE0 starting and ending configurations are depicted in Fig. $5 \mathrm{~h}-\mathrm{b}$. It is reasonable to assume that the PBE0 value is more accurate. However, 


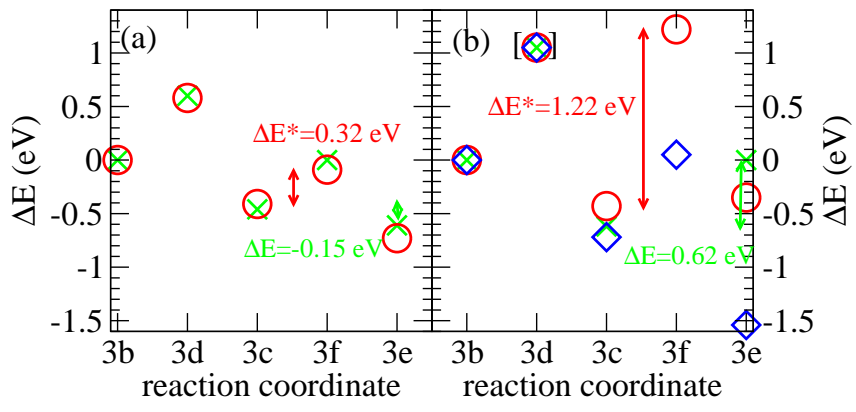

FIG. 4: Relative energies and energy barriers, in eV, associated with further reactions of EC fragments on LMO and LNMO (001) surfaces. Panels (a) and (b) refer to DFT+U and PBE0 calculations, respectively. Green, red, and blue (only in (b)) are for $\mathrm{Li}_{0.5} \mathrm{Mn}_{2} \mathrm{O}_{4}, \mathrm{Li}_{0.5} \mathrm{Ni}_{0.5} \mathrm{Mn}_{1.5} \mathrm{O}_{4}$, and $\mathrm{Li}_{0.2} \mathrm{Ni}_{0.5} \mathrm{Mn}_{1.5} \mathrm{O}_{4}$ respectively. The $x$-axis refers to Fig. 3 panels; LNMO configurations are similar to LMO ones in Fig. 3. The bracket in (b) means that the PBE0 proton transfer $\Delta E^{*}$ are not calculated, but are assumed to be similar to that associated with Fig. 2 $\mathrm{d}$. The two-sided arrows indicate the two key differences between (a) DFT $+\mathrm{U}$ and (b) PBE0. PBE0 predicts that the final reaction on $\mathrm{Li}_{0.5} \mathrm{Ni}_{0.5} \mathrm{Mn}_{1.5} \mathrm{O}_{4}$ has a much higher $\Delta E^{*}$ than DFT+U, and that $\Delta E$ for the final reaction on $\mathrm{Li}_{0.5} \mathrm{Mn}_{2} \mathrm{O}_{4}$ is much more unfavorable than $\mathrm{DFT}+\mathrm{U}$.

for the purpose of modeling further oxidizing reactions, we should remove more $\mathrm{Li}$ atoms to partially offset the $e^{-}$transferred from EC to the LMO slab so as to maintain high voltages. Next we eliminate the Li directly coordinated to the surface $\mathrm{O}^{2-}$ anion being dragged by the EC fragment off the surface (labeled "O" in Fig. 囵) to yield a $\mathrm{Li}_{0.5} \mathrm{Mn}_{2} \mathrm{O}_{4}$ stoichiometry. Now the equilivalent of Fig. 5 b, but with one less Li, becomes exothermic $(\Delta E=-0.25 \mathrm{eV}$, not show in Fig. 15) relative to Fig. (5;, suggesting that this step should proceed. The overall Li-removal from Fig. 5 a yields a $+4.70 \mathrm{~V}$ equilibrium voltage if one takes into account lithium metal cohesive energy. (Here "equilibrium" means "electrochemical equilibrium" 91 see Fig. 7b below.) Thus a $4.70 \mathrm{~V}$ potential appears necessary for further EC oxidation on LMO. By comparison, this requirement is found to be only $4.33 \mathrm{~V}$ in $\mathrm{DFT}+\mathrm{U}$ calculations.

The next deprotonation step (Fig. 3b $\rightarrow$ Fig. 3r) is predicted to be exothermic using both $\mathrm{DFT}+\mathrm{U}$ and PBE0 functionals (Fig. 4a-b). Since this is another proton transfer, we assume that the PBE0 $\Delta E^{*}$ is not dissimilar to the $\Delta E^{*}$ computed in Fig. 22 for that H-transfer

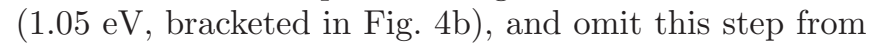
PBE0 consideration.

Instead we focus on the final step. For $\mathrm{Li}_{0.5} \mathrm{Mn}_{2} \mathrm{O}_{4}$, PBE0 predicts that the Fig. 3. $\rightarrow$ Fig. 3r reaction, associated with $\mathrm{CO}_{2}$ and $\mathrm{C}_{2} \mathrm{H}_{2} \mathrm{O}_{2}$ release, exhibits $\Delta E=0.62 \mathrm{eV}$. This is far more endothermic than the

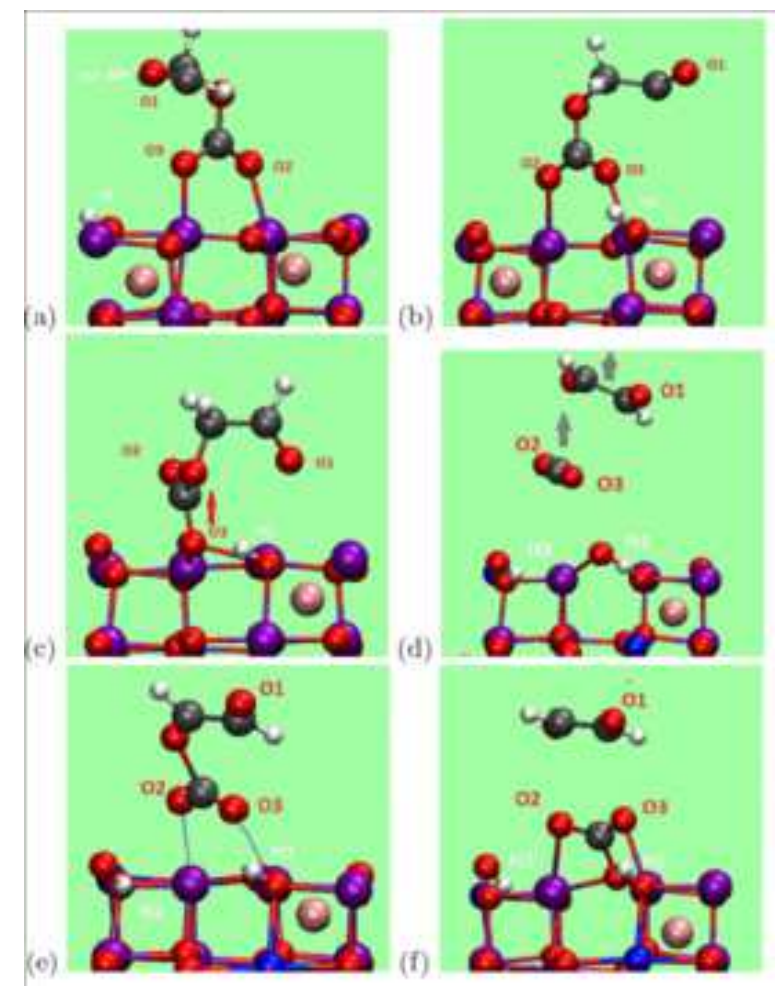

FIG. 5: Selected LMO and LNMO configurations obtained using PBE0 calculations. (a)-(b) Before/after dragging $\mathrm{O}^{2-}$ anion off $\mathrm{Li}_{0.6} \mathrm{Mn}_{2} \mathrm{O}_{4}$ (001) surface. (c) Removing one Li from panel (a). (d)-(e) Final configuration and transition state for EC oxidation on $\mathrm{Li}_{0.5} \mathrm{Ni}_{0.5} \mathrm{Mn}_{1.5} \mathrm{O}_{4}$, respectively. (f) $\mathrm{CO}_{2}$ readsorbs on $\mathrm{Li}_{0.5} \mathrm{Ni}_{0.5} \mathrm{Mn}_{1.5} \mathrm{O}_{4}$. The $\mathrm{Ni}$ cation on the surface in panels (d)-(f) is slightly obscured by the leftmost $\mathrm{OH}$ group; see Fig. 3h for clarity.

$\mathrm{DFT}+\mathrm{U}$ prediction (Fig. 4. We speculate that the $\mathrm{DFT}+\mathrm{U}$ parameter for $\mathrm{Mn}$ is fitted to $\mathrm{Mn}(\mathrm{III}) / \mathrm{Mn}(\mathrm{IV})$ solid state electrochemistry and may overestimate the stability of the $\mathrm{Mn}(\mathrm{II})$ found in Fig. 3 ,

Fig. $5 \mathrm{~d}$ depicts the product of the $\mathrm{CO}_{2}$ release reaction on $\mathrm{Li}_{0.5} \mathrm{Ni}_{0.5} \mathrm{Mn}_{1.5} \mathrm{O}_{4}$, instead of $\mathrm{LMO}$, at the same Li content. While the EC fragment configuration superficially resembles that on LMO surfaces, the presence of $\mathrm{Ni}$ makes this reaction far less endothermic $(\Delta E=0.08 \mathrm{eV}$ Fig. (4). $\mathrm{CO}_{2}$ release should be accompanied by the typical favorable entropy of $\sim 0.4-0.5 \mathrm{eV}$ at $\mathrm{T}=300 \mathrm{~K}$ at estimated gas pressure of $0.1 \mathrm{~atm} . \stackrel{35}{\underline{3}}$ which offsets the $0.08 \mathrm{eV}$ endothermicity. In fact, all steps of further EC oxidation we have examined so far with the PBE0 method (Fig. 3, Fig. 5) are more favorable on LNMO (001) than LMO (001) slabs at the same $50 \%$ Li content (Fig. 47). Just by considering energetic differences, the PBE0 functional (unlike DFT $+\mathrm{U}$ ) already distinguishes oxidation on LNMO from that on LMO.

Next we examine the kinetics associated with $\mathrm{CO}_{2}$ release on LNMO. The $\Delta E^{*}$ predicted at the PBE0 transition state (Fig. 5) is larger than the $\mathrm{DFT}+\mathrm{U}$ value by a factor of 3.5 (Fig. (4). Whereas the DFT+U $\Delta E^{*}$ 
is consistent with a fast reaction, the PBE0 value of $\Delta E^{*}=1.22 \mathrm{eV}$ suggests that the organic fragment shown in Fig. $3 \mathrm{~d}$ should persist over beyond battery operation time scales on $\mathrm{Li}_{0.5} \mathrm{Ni}_{0.5} \mathrm{Mn}_{1.5} \mathrm{O}_{4}$ at $\mathrm{T}=300 \mathrm{~K}$. (Note that the Fig. 5. transition state does not involve proton transfer, and a large zero point correction is not expected.) We have not repeated the similar reaction on LMO surface because LMO is expected to be even less oxidative than high-voltage LNMO at the same Li content. It is perhaps not surprising that this complex transition state proves problematic for the $\mathrm{DFT}+\mathrm{U}$ functional. The unusual reaction involves the simultaneous transfer of $e^{-}$, breaking of a $\mathrm{C}-\mathrm{O}$ covalent bond, and the removal of two oxygen-surface metal coordination. In Fig. 5e, the C-O bond distance is $1.71 \AA$, which is $0.24 \AA$ shorter than the $1.95 \AA$ predicted using DFT $+\mathrm{U}$. More conventional reactions, such as that $\mathrm{C}-\mathrm{O}$ bond cleavage reaction in $\mathrm{CO}_{3}^{2-}$, exhibit $\Delta E^{*}$ which are less sensitive to choice of hybrid or non-hybrid DFT functional ${ }^{38}$

For $\mathrm{CO}_{2}$ release to occur, the gas molecule must not re-coordinate to the oxide surface. In the PBE0 NEB barrier calculation, we accidentally come across a configuration where the released $\mathrm{CO}_{2}$ adsorbs via another surface $\mathrm{O}$, reconstituting a $\mathrm{CO}_{3}^{2-}$ motif (Fig. $5 \mathrm{f}$ ). This configuration is $0.49 \mathrm{eV}$ more favorable than Fig. $5 \mathrm{k}$ at zero temperature. Thus, even with the gas entropy gained at $\mathrm{T}=300 \mathrm{~K}, \mathrm{CO}_{2}$ release from the (001) surface of $\mathrm{Li}_{0.5} \mathrm{Ni}_{0.5} \mathrm{Mn}_{1.5} \mathrm{O}_{4}$ is arguably barely favorable.

Finally, we examine PBE0 predictions at higher equilibrium voltages. We lower the Li-content to $20 \%$ $\left(\mathrm{Li}_{0.2} \mathrm{Ni}_{0.5} \mathrm{Mn}_{1.5} \mathrm{O}_{4}\right)$ (not shown in figures), which should raise the equilibrium cathode voltage. With this change in Li-content, the blue diamonds in Fig. 4 $4 \mathrm{~s}$ indicate that the last two steps of the reaction are now both exothermic, $\Delta E=-0.72$ and $-0.82 \mathrm{eV}$, respectively. The final, $\mathrm{CO}_{2}$-releasing step now exhibits a much lower $\Delta E^{*}=+0.77 \mathrm{eV}$ instead of the $+1.22 \mathrm{eV}$ at $x=0.5$. According to Eq. 1. $\mathrm{CO}_{2}$ release occurs in sub-second time

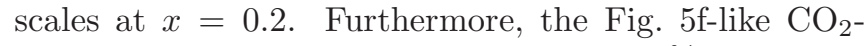
adsorption configuration appropriate to $20 \% \mathrm{Li}$ content exhibits a weak $\mathrm{CO}_{2}$ binding energy of $\Delta E=-0.36 \mathrm{eV}$, compared to $-0.49 \mathrm{eV}$ at $x=0.5$. In other words, as $\mathrm{Mn}$ and $\mathrm{Ni}$ cations acquire larger charges, $\mathrm{O}^{2-}$ anions coordinated to them exihbit weaker covalent bonds with $\mathrm{CO}_{2}$ molecules. This $\Delta E$ will not retain $\mathrm{CO}_{2}$ on the surface because of the $\sim 0.4 \mathrm{eV}$ entropy gain upon gas release at $\mathrm{T}=300 \mathrm{~K}$ at $0.1 \mathrm{~atm}$

In summary, the more accurate PBE0 method predicts that $\mathrm{CO}_{2}$ release is not energetically favorable on LMO (001) surfaces at 50\% Li-content. Even on LNMO (001) at the same Li-content, which should represent a higher equilibrium potential than $4.3 \mathrm{~V}, \mathrm{CO}_{2}$ release remains energetically and kinetically hindered. Only at lower Li-content (20\%, which corresponds to an even higher equilibrium voltage) does $\mathrm{CO}_{2}$ release become fast. The partially oxidized EC fragment is now completely eliminated from the surface (Fig. 怔). Cleared of adsorbed (a)

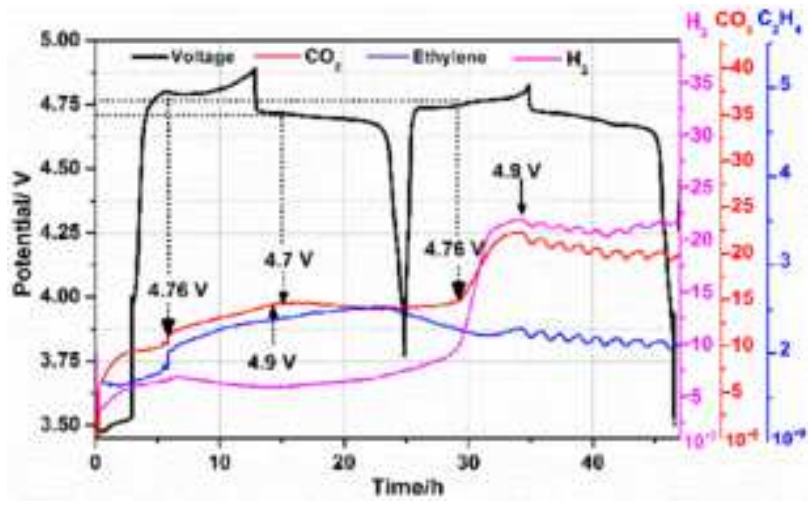

(b)

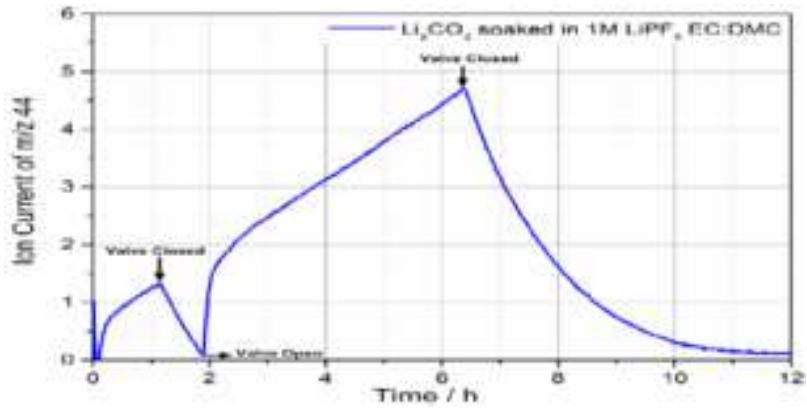

FIG. 6: (a) Galvanostatic charge/discharge profiles (black) and in-operando online electrochemical mass spectrometric analysis of evolved gases as a function of applied potential during galvanostatic cycling of a LNMO half-cell in $1 \mathrm{M} \mathrm{LiPF}_{6}$ in EC:DMC (1:1). (b) OEMS evolution trends indicating the evolution of $\mathrm{CO}_{2}$ as a byproduct of spontaneous $\mathrm{Li}_{2} \mathrm{CO}_{3}$ dissolution in the electrolyte solution."

species, the surface can now continuously react with solvent molecules (Fig. 11). Unlike PBE0, DFT+U fails to predict this two-step behavior or to distinguish between LMO and LNMO.

We have not computed the precise $\mathrm{CO}_{2}$ release onset voltage. This is partly because the electronic voltage $\underline{11}$ is not readily specified in polaronic conductors like LMO and LNMO (see Sec. IIIE below). Other CEI components have been proposed; $; \underline{\underline{6}}$ one of them is examined in the S.I., and found to react at moderate Li-content without releasing $\mathrm{CO}_{2}$.

\section{OEMS Measurements}

To support the theoretical calculations with experimental proofs, we carried out in-operando analysis of gaseous evolution as a function of applied potential using online electrochemical mass spectrometry (OEMS) of LNMO in $1 \mathrm{M} \mathrm{LiPF}_{6}$ in EC:DMC (1:1). The observed evolution of $\mathrm{H}_{2}, \mathrm{CO}_{2}$, and $\mathrm{C}_{2} \mathrm{H}_{4}$ during galvanostatic charge/discharge is depicted in Fig. 6a .

The evolution of $\mathrm{C}_{2} \mathrm{H}_{4}(\mathrm{~m} / z=28)$ at the beginning of first charge is likely associated with the SEI formation at the anode side through reductive decomposition of ethy- 
lene carbonate from the electrolytic solution, $\underline{\underline{49}}$ We assigned the evolution trend at $m / z=28$ to ethylene; however, partial contribution from $\mathrm{CO}$ cannot be eliminated. By carefully looking at the $\mathrm{CO}_{2}$ evolution, it can be seen that $\mathrm{CO}_{2}$ starts evolving in the OCV period which can be attributed to the spontaneous reaction between the electrolyte and the electrode. This evolution attains equilibrium during the rest period. During charge to voltages higher than $4.75 \mathrm{~V}$, another evolution of $\mathrm{CO}_{2}$ is observed. A maximum in the $\mathrm{CO}_{2}$ evolution was observed at $4.9 \mathrm{~V}$. It is important to note that in OEMS studies, the system is not washed with inert gas during measurements. This fact enables us to continuously measure in-operando the volatile components in the battery cell, without changing its composition and without stopping cascades of reactions that take place. However, due to this unique approach, remaining gas species are constantly detected (e.g. $\mathrm{CO}_{2}$ ); hence our discussion always focuses on increase/decrease in evolution and local maxima/minima. During the discharge, when the lithiation level of the LNMO increases and the potential goes below $4.7 \mathrm{~V}$, the release of $\mathrm{CO}_{2}$ is reduced.

The onset of $\mathrm{CO}_{2}$ evolution in the second cycle during the initiation of the second plateau at $4.75 \mathrm{~V}$ further confirms the validity of the calculated results; the evolution of $\mathrm{CO}_{2}$ from $\mathrm{CEI}$ decomposition occurs mainly at lower Li-content and higher voltage. Note also that our calculations focus on the EC molecule; other electrolyte species present in Fig. 6 6 , such as DMC, may yield more gas products during CEI formation at lower voltages. $\mathrm{H}_{2}$ also exhibited similar pattern of evolution which indicates close involvement of $\mathrm{H}^{+}$in the degradation of electrolyte and evolution of $\mathrm{CO}_{2}$. This may also in accordance to the predicted transfer of $\mathrm{H}^{+}$and electron in the EC decomposition, with the caveat that the contribution of anode side to the $\mathrm{H}_{2}$ formation cannot be differentiated. We apply OEMS with a half cell (lithium counter/reference electrode). While OEMS has obvious advantages, our set-up is arguably not well-suited to pinpoint the source of gases. At least one recent of modification of DEMS $\underline{49}$ seems able to differentiate anode and cathode gas contributions. That work also identifies $\mathrm{H}_{2}$, $\mathrm{CO}$, and $\mathrm{CO}_{2}$ products from the cathode.

Next we address the question of how LNMO surfaces can become exposed to the liquid electrolyte despite the fact that as-synthesized cathode oxide materials tend to be covered with native $\mathrm{Li}_{2} \mathrm{CO}_{3}$ films. We perform experiments where $\mathrm{Li}_{2} \mathrm{CO}_{3}$ particles are soaked in electrolyte with/without $\mathrm{LiPF}_{6}$. These experiments are performed under storage conditions, without applied voltages. We find that $\mathrm{Li}_{2} \mathrm{CO}_{3}$ dissolves in electrolyte solution as well as in pure DMC solvent (in absence of $\mathrm{LiPF}_{6}$ salt) - although the latter is much-suppressed. The dissolution is qualitatively consistent with previous studies $\frac{9,90}{} \mathrm{In}$ the video included in the S.I., the left vial is with $0.1 \mathrm{~g}$ $\mathrm{Li}_{2} \mathrm{CO}_{3}$ in $20 \mathrm{~mL}$ of LP30 electrolyte solution, and the right vial has the same amount of $\mathrm{Li}_{2} \mathrm{CO}_{3}$ in $20 \mathrm{~mL}$ DMC
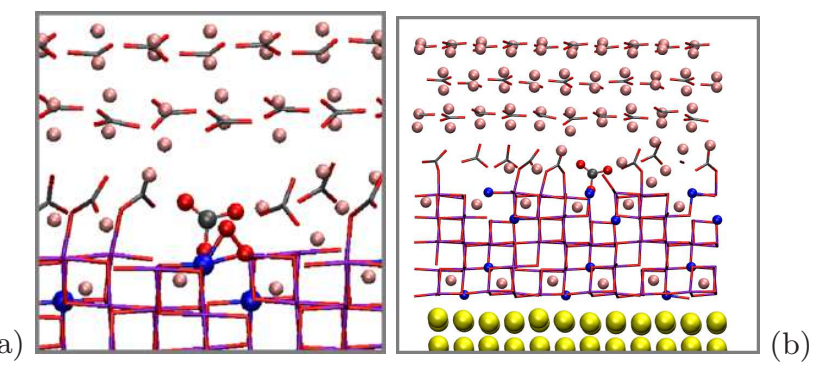

FIG. 7: (a) First reaction products at $\mathrm{Li}_{2} \mathrm{CO}_{3}(0001) / \mathrm{LNMO}$ (001) interface, including a $\mathrm{O}_{2}^{\delta-}$; (b) reaction energetics are almost identifical to panel (a) are predicted when a $\mathrm{Au}$ "current collector" is added to the backside of the oxide slab.

(no $\mathrm{LiPF}_{6}$ ). In $\mathrm{DMC}$ the $\mathrm{Li}_{2} \mathrm{CO}_{3}$ settles down immediately (swirling motion of particles can be seen), whereas it remains suspended for much longer in the presence of $\mathrm{LiPF}_{6}$ (LP 30) indicating more gas bubbles adsorbed to $\mathrm{Li}_{2} \mathrm{CO}_{3}$ there, and more chance for dissolution. In neither cases do we see complete dissolution of the $\mathrm{Li}_{2} \mathrm{CO}_{3}$, which is likely in excess. This finding suggests that whether native $\mathrm{Li}_{2} \mathrm{CO}_{3}$ films on oxide surfaces are removed upon soaking in the electrolyte depend on the initial film thickness and electrolyte composition, including impurities present. Fig. $6 \mathrm{~b}$ depicts OEMS response of $\mathrm{Li}_{2} \mathrm{CO}_{3}$ soaked in LP30 solution; it confirms that $\mathrm{CO}_{2}$ is evolved as a dissolution product.

\section{E. $\mathrm{Li}_{2} \mathrm{CO}_{3}$ Reaction on LNMO surfaces (DFT+U)}

The next two subsections consider oxidation of inorganic $\mathrm{Li}_{2} \mathrm{CO}_{3}$ films $\stackrel{71}{ }$ They suggest alternative mechanisms of $\mathrm{Li}_{2} \mathrm{CO}_{3}$ removal prior to LNMO surfaces reacting with the liquid electrolyte, and complement our work on organic CEI components.

In the S.I., we argue that oxidation of $\mathrm{Li}_{2} \mathrm{CO}_{3}$ should initiate at interfaces rather than start from the bulk. Here we first consider the interface between its $\mathrm{Li}_{2} \mathrm{CO}_{3}$ (0001) ${ }^{92.93}$ and LNMO (001). In brief, we find that, to the extent the predicted $\Delta E$ and $\Delta E^{*}$ permit oxidation reactions, they are consistent with the release of triplet $\mathrm{O}_{2}$ gas, not $\mathrm{CO}_{2}$ gas (Fig. $7 \mathrm{a}$ ). This is at variance with experimental results $\stackrel{71}{\underline{1}}$ Hence we only highlight one aspect of the results and leave most details to the S.I.

The interface between LNMO (001) and $\mathrm{Li}_{2} \mathrm{CO}_{3}$ (Fig. 7h) is Li-deficient, and is likely "metallic." Fig. S3 in the S.I. confirms the interfacial region has no band gap. Due to this metallic behavior, the electronic voltage $\left(V_{e}\right)$ can be readily computed as the LNMO work function modified by its interface with $\mathrm{Li}_{2} \mathrm{CO}_{3}$ via the Trasatti relation, $91,94,95$ provided that the electrolyte contribution is neglected. The computed $V_{e}$ and the voltage based on Li-insertion energetics must match to ensure that simulation cells containing interfaces are at "equilibrium," not at overpotential conditions. We obtain an 
electronic voltage of $V_{e}=4.56 \mathrm{~V}$. This value is reasonably close to the $4.75 \mathrm{~V}$ found by adding/subtracting Li-atoms. In other words, the model system is not at a significant overpotential. A more general way to compute $V_{e}$, even when the electrode has a band gap, is to place an inert metallic electrode underneath ${ }^{91}$ Upon adding a $\mathrm{Au}$ (001) "current collector" (Fig. [7b), $V_{e}$ is found to an almost indistinguishable $4.58 \mathrm{~V}$. Therefore the metallic nature of the thin interface between $\mathrm{LNMO}$ and $\mathrm{Li}_{2} \mathrm{CO}_{3}$ should be sufficent for establishing the electronic potential. The $\Delta E$ of the reaction associated with $\mathrm{CO}_{3}^{2-}$ reaction to form $\mathrm{O}_{2}^{\delta-}$ is also very similar to the slab model without the Au slab. This dovetails with our experience that redox reactions on cathode surfaces, which involve discrete changes in occupancies of transition metal ion $d$-orbitals at orbital energies below the Fermi level (S.I.), are not sensitive to $V_{e}, 91$ anodes $\frac{96}{6}$ Therefore we have not made further modifications of the interfaces to bring $V_{e}$ closer to $4.75 \mathrm{~V}$.

There is no metallic character to the LNMO slabs in the previous sections. The cost of PBE0 calculations there makes adding a metallic "current collector" beneath the LNMO (001) difficult, and this impedes effort to calculate $V_{e}$. Along with the small cell sizes, this is one reason we have not reported $\mathrm{CO}_{2}$ release onset voltages.

\section{F. Reaction between $\mathrm{Li}_{2} \mathrm{CO}_{3}$ and Solvent Molecules}

Finally, we explore electrolyte oxidative reactions on the outer, partially delithiated $\mathrm{Li}_{2} \mathrm{CO}_{3}$ (0001) surface. The PBE functional is applied. As no transition metal ion is present in this section, $\mathrm{DFT}+\mathrm{U}$ and $\mathrm{PBE}$ are equivalent.

Fig. 8 depicts the (0001) surface with a single physisorbed EC molecule. There should be $8 \mathrm{Li}^{+}$on each layer of $\mathrm{Li}_{2} \mathrm{CO}_{3}$ in the simulation cell periodically replicated in the lateral dimensions. The top layer has half its $\mathrm{Li}$ atoms removed to qualitatively mimic high voltage conditions. The simulation cell remains charge-neutral.

We explore a reaction mechanism similar to that for EC oxidation on LMO (001) (Fig. 20, $\frac{53}{5}$ In Fig. 8b, the EC is chemisorbed with a bent molecular geometry. This is endothermic by $\Delta E=+0.69 \mathrm{eV}$ (Fig 9). Such a configuration change should exhibit no barrier 53 The carbonyl carbon atom is now 4-coordinated. Fig. 8k depicts a subsequent configuration with a broken $\mathrm{C}-\mathrm{O}$ bond, opening the EC 5-member ring and restoring 3-coordination to what was the carbonyl C-atom. The reaction is exothermic by $-0.33 \mathrm{eV}$ compared with the bent configuration (Fig. 8b), but endothermic by $+0.35 \mathrm{eV}$ relative to physisorption (Fig. [ 8 a). The barrier is $\Delta E^{*}=0 .+27 \mathrm{eV}$ relative to Fig. 8b (+0.96 eV relative to Fig. 8 $\mathrm{a})$.

The next step is postulated to involve the transfer of a ethylene proton to a nearby oxygen group, in accordance with EC oxidation on oxide surfaces $\underline{53}$ Unlike LMO or LNMO (001), O atoms on the $\mathrm{Li}_{2} \mathrm{CO}_{3}$ (0001)

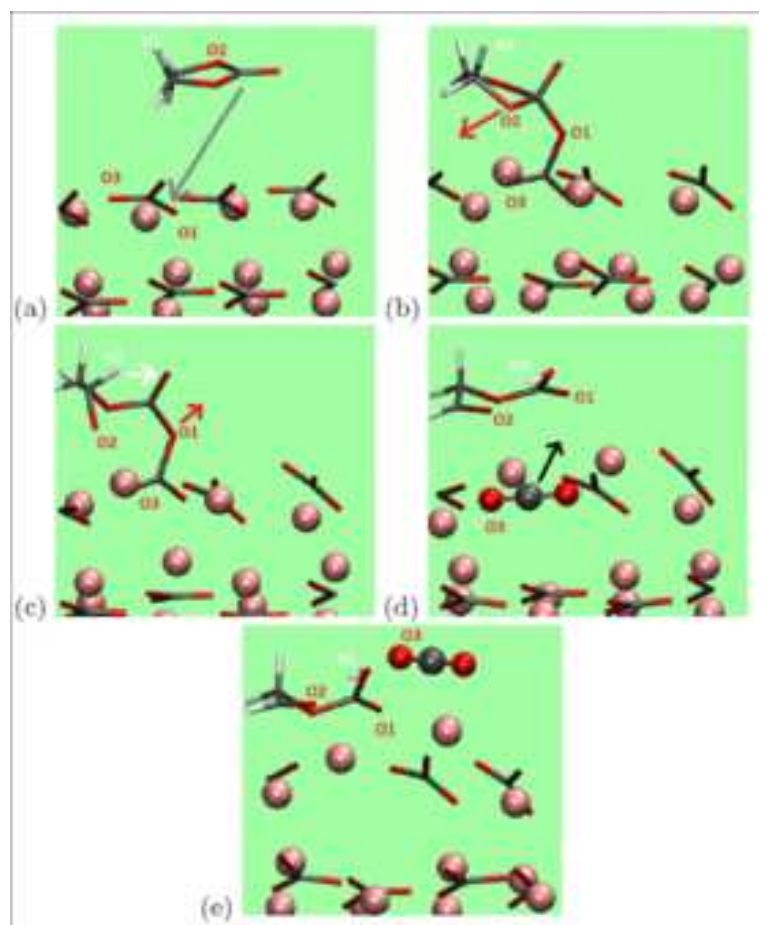

FIG. 8: EC oxidative decomposition on a partially delithated $\mathrm{Li}_{2} \mathrm{CO}_{3}$ (0001) surface. (a) Physisorbed configuration; (b) EC adsorbed in a bent geometry; (c) broken EC C-O bond; (d) proton transfer from EC to lithium carbonate and breaking of $\mathrm{O}-\mathrm{C}$ bond, forming a $\mathrm{CO}_{2}$; (e) release of $\mathrm{CO}_{2}$ as gas molecule.

surface are far away from all protons. When an $\mathrm{H}$-atom is moved from an EC fragment $\mathrm{C}$ atom to a surface $\mathrm{CO}_{3}^{2-}$ group and the configuration is optimized, we find that the proton spontaneous migrates to an oxygen atom on the $\mathrm{ROCO}_{2}^{2-}$ group on the EC fragment instead (Fig. 8 $\mathrm{d}$ ). Simultaneously, a C-O bond is broken, yielding a $\mathrm{CO}_{2}$ on the $\mathrm{Li}_{2} \mathrm{CO}_{3}$ surface. This H-transfer step is accompanied by $e^{-}$transfer (oxidation) and is overall oxothermic, $\Delta E=-1.86 \mathrm{eV}$, relative to physisorption. The barrier is $\Delta E=0.18 \mathrm{eV}$ relative to Fig. $8 \mathrm{r}$. In Fig. 8 , the $\mathrm{CO}_{2}$ lodged on the surface is released alongside an additional $\Delta E=-0.84 \mathrm{eV}$ with a local $\Delta E^{*}=+0.82 \mathrm{eV}$ barrier. Overall, the highest activation energy among these steps is $0.96 \mathrm{eV}$. These reactions at the electrolyte $/ \mathrm{Li}_{2} \mathrm{CO}_{3}$ interface yield more favorable $\Delta E$ and $\Delta E^{*}$ than at the $\mathrm{LNMO} / \mathrm{Li}_{2} \mathrm{CO}_{3}$ interface (S.I.).

This reaction pathway represents an alternative to that suggested in Ref. 72, namely that singlet $\mathrm{O}_{2}$ is released during oxidationwhich then attacks the liquid electrolyte. We stress that this section represents an exploratory plausibility demonstration. We have not exhaustively explored other mechanisms, nor have we applied the PBE0 functional to check $\Delta E^{*}$. The precise voltage/lithium content relation for this reaction has not been determined. Despite these caveats, this section suggests that EC reactions with surface-delithiated $\mathrm{Li}_{2} \mathrm{CO}_{3}$ to release $\mathrm{CO}_{2}$ are viable. Even accounting for possible DFT $+\mathrm{U}$ 


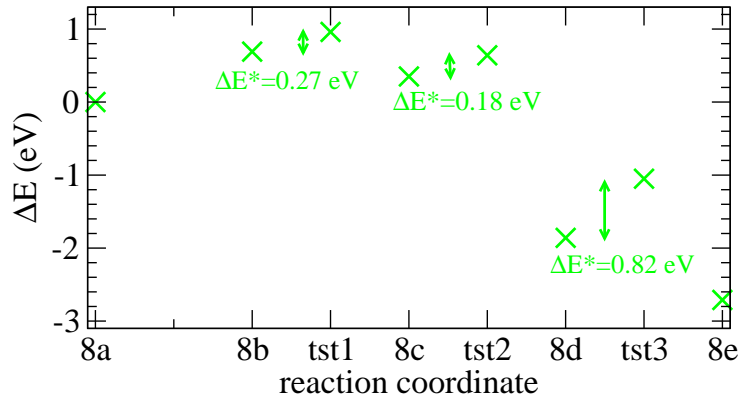

FIG. 9: PBE relative energies and energy barriers, in $\mathrm{eV}$, associated with EC oxidation on partially delithiated $\mathrm{Li}_{2} \mathrm{CO}_{3}$ (0001) surfaces (Fig. 8). The $x$-axis labels refer to the panels in Fig. 8. The three transition states are not depicted in Fig. 8

$\Delta E^{*}$ errors, sufficiently high voltage will likely make the $\mathrm{EC} / \mathrm{Li}_{x} \mathrm{CO}_{3}$ reaction sufficiently favorable to occur in one-hour time scales, just like it does for EC fragment oxidation on LNMO surfaces.

\section{G. Further Discussions}

The further oxidation of our model CEI products involves the simultaneous transfer of $\mathrm{H}^{+}$and $e^{-}$. The role of proton transfer in enabling oxidation of organic components has been emphasized in the presence of counter ions and at multiple battery interfaces $; \underline{50,53} \underline{-62}$ its importance cannot be overstated. One product of our predicted oxidative decomposition is $\mathrm{C}_{2} \mathrm{H}_{2} \mathrm{O}_{2}$, known to be a polymerizing agent. This appears consistent with polymeric CEI species routinely reported on cathode surfaces $\underline{12} \underline{\underline{14}}$ although other mechanisms can lead to polymers.

Oxidation of organic molecules and fragments on cathode oxide surfaces inject electrons into transition metal ions therein. To offset this electrochemical reduction and to maintain a constant potential, Li atoms should be removed (with $\mathrm{Li}^{+}$diffusing into the electrolyte). Ideally, the grand canonical Monte Carlo (GCMC) technique should be combined with DFT calculations for this purpose; so far DFT-based MC is in its infancy $\underline{\underline{99}}$

We propose a multi-step electrolyte oxidation pathway (Fig. 13), which is also suggested for oxidation on Pt surfaces $\frac{16}{16}$ Electrolytes with fluorinated solvent molecules exhibits increased anodic stability $\underset{7}{7}, \underline{.}$ This behavior is not inconsistent with our hypothesis, because CEI formed from fluorinated molecules should also be more stable against oxidation than CEI formed from standard organic battery electrolytes. This hypothesis is not inconsistent with Ref. 52, which predicts a onestep release of $\mathrm{CO}_{2}$ from intact $\mathrm{EC}$ molecules adsorbed on a pristine LNMO (001) surface. Such a direct $\mathrm{CO}_{2}$ release route could take place in a voltage regime where all organic CEI products have been oxidized and removed from LNMO surfaces.

The reported voltage onset associated with $\mathrm{CO}_{2}$ release varies in the literature. He et al., 42 Michalak et al. $\stackrel{48}{4}$ and $\mathrm{Xu}$ et al $\underline{\underline{46}}$ have reported $\mathrm{CO}_{2}$ release below $5.0 \mathrm{~V}(4.8 \mathrm{~V}$, $4.6 \mathrm{~V}$, and $4.8 \mathrm{~V}$ respectively), while Jusys et al $\stackrel{49}{\underline{4}}$ and Jung et al. $\underline{44}$ have reported $\sim 5.0 \mathrm{~V}$ and $>5.4 \mathrm{~V}$, respectively. Our reported OEMS results are meant to be a check on this issue. We report $4.75 \mathrm{~V}$ (Fig. 6), which is in alignment with Refs. 42,46, 48. The differences may arise from charging rates, anode choices $\frac{97}{9}$ electrolytes impurities, 98 temperatures, and the initial surface termination of cathode oxide materials. Interestingly, high-Ni content layered NMC materials are reported to release $\mathrm{CO}_{2}$ at much lower voltages than LNMO $\underline{44}$ In another report $\stackrel{42}{=} \mathrm{DMC}$ is found to be more reactive than $\mathrm{EC}$ on LNMO. Our calculations have focused on LNMO (001) due to the small cell size that permits PBE0-based calculations, and on EC because we have performed previous studies $\frac{53,54}{1 n}$ the future, extending our method to DMC, NMC, counter-ions, ond the (111) facet will give interesting comparisons.

$\mathrm{CO}$ release hve been reported at elevated voltages. $\mathrm{CO}$ cannot emerge from the mechanism investigated herein, and will be considered in the future.

\section{CONCLUSIONS}

We have applied the hybrid PBE0 DFT functional to compute the energetics and kinetics associated with key steps of interfacial oxidation of model cathode electrolyte interphase (CEI) components on high voltage spinel $\left(\mathrm{Li}_{x} \mathrm{Ni}_{0.5} \mathrm{Mn}_{1.5} \mathrm{O}_{4}\right.$ or LNMO) (001) surfaces. Our model CEI components are partially oxidized ethylene carbonate (EC) molecules from previous computational studies $\stackrel{53}{n}$ At moderate Li-content $(x=0.5)$, the oxidative reaction barrier $\Delta E^{*}$ is too high. At much lower Licontent $(x=0.2)$ which corresponds to higher equilibrium voltages, $\Delta E^{*}$ decreases, and the oxidative reaction occurs within 1-hour battery charging time scales. This leads to removal of adsorbed organic fragments from this surface and release of $\mathrm{CO}_{2}$ molecules. The precise onset voltage cannot yet be determined. Spinel oxides not doped with $\mathrm{Ni}$, i.e., $\mathrm{Li}_{x} \mathrm{Mn}_{2} \mathrm{O}_{4}$ (LMO), exhibits reaction energies $(\Delta E)$ far less favorable towards $\mathrm{CO}_{2}$ release compared with LNMO.

We also apply the DFT/PBE0 method to re-examine oxidation kinetics of intact EC molecules on LMO (001) surfaces at $40 \%$ charge $(x=0.6) . \Delta E$ and $\Delta E^{*}$ for the key oxidative step are predicted to be $-1.75 \mathrm{eV}$ and $1.05 \mathrm{eV}$, respectively, to yield adsorbed species which are the CEI components discussed in the last paragraph. This $1.05 \mathrm{eV}$ barrier is much lower than the $\Delta E^{*}$ for a subsequent CEI oxidation reaction at similar Li-content $(x=0.5)$, and is further reduced by zero point corrections. 
From these predictions, our PBE0 calculations are consistent with a two-step process. First EC solvent molecules are oxidized at modest voltages and $\mathrm{Li}$ contents. The partially decomposed EC fragment remains on the LMO and LNMO (001) surfaces, covering up the reactive transition metal ion sites. At sufficiently high voltages on LNMO (001), these fragments are oxidized, releasing $\mathrm{CO}_{2}$ gas and clearing the surface for further, uncontrolled reactions with the liquid electrolyte. LMO likely behaves similarly at sufficiently high voltages, but we have not demonstrated this expliclty. Fluoride- and phosphorus-containing CEI products have not been considered in this work.

The widely applied DFT $+\mathrm{U}$ method, based on the $\mathrm{PBE}$ functional, is useful for predicting qualitative oxidative mechanisms. However, unlike PBE0, it predicts $\Delta E$ and $\Delta E^{*}$ which are favorable for oxidation of both EC and adsorbed, partially decomposed EC fragments - even at the modest equilibrium potentials associated with $\mathrm{Li}_{0.5} \mathrm{Mn}_{2} \mathrm{O}_{4}$. This does not appear to agree our online electrochemical mass spectroscopy (OEMS) measurements and those of other groups. This strongly suggests that hybrid DFT functionals should be used to spotcheck electrolyte oxidation predictions. Nevertheless, we have used the more economic $\mathrm{DFT}+\mathrm{U}$ method for an exploratory investigation of oxidation of native $\mathrm{Li}_{2} \mathrm{CO}_{3}$ films on cathode oxides. We conclude that oxidation of $\mathrm{Li}_{2} \mathrm{CO}_{3}$ is more likely to first occur on the outer $\mathrm{Li}_{2} \mathrm{CO}_{3}$ surface in contact with liquid electrolytes, than on its inner surface in contact with cathode oxide materials.

All DFT/PBE0 calculations of the model slabs without $\mathrm{Li}_{2} \mathrm{CO}_{3}$ films yield a band gap. Hence there are no delocalized "surface states" - the redox-active states are simply $d$-orbitals localized on surface $\mathrm{Mn}$ and $\mathrm{Ni}$ transition metal ions. Higher voltages yield more Ni(IV), $\mathrm{Ni}(\mathrm{III})$, and $\mathrm{Mn}(\mathrm{IV})$ cations and accelerate organic CEI degradation reactions. Two general conclusions that can be drawn from our specific PBE0 functional calculations are: $\mathrm{PBE} 0$ is probably more accurate than $\mathrm{DFT}+\mathrm{U}$ when applied to $\mathrm{Mn}(\mathrm{II}) / \mathrm{Mn}$ (III) redox couple. PBE0 predicts higher reaction barriers associated with $\mathrm{C}-\mathrm{H}$ and $\mathrm{C}-\mathrm{O}$ bond-breaking, especially in reactions that releases $\mathrm{CO}_{2}$.

This comparative study on EC, organic CEI component, and $\mathrm{Li}_{2} \mathrm{CO}_{3}$ oxidation highlights the importance of multi-step reactions, and emphasizes the need to examine the oxidation of $\mathrm{CEI} /$ surface films, not just intact solvent molecules. Differentiating CEI and solvent oxidation events under high voltage conditions should lead to new insights that inform cathode passivation strategies.

\section{Supplementary Material}

See supplementary material for simulation cell size effects; the reactions of $\mathrm{Li}_{2} \mathrm{CO}_{3}$ on LNMO (001); reactions between EC molecules and other oxide surfaces; oxidation of other proposed CEI components, rationale for using PBE0; rationale for single molecule slab models; optimized PBE0 configurations; and a video showing the reaction between $\mathrm{Li}_{2} \mathrm{CO}_{3}$ and liquid electrolytes under storage conditions.

\section{Acknowledgements}

We thank Shen Dillon for careful reading of an early draft, and Angelique Jarry, Dale Huber, Jacob Harvey, Katharine Harrison, Christine James, and Yue Qi for useful discussions. MN would like to acknowledge the Funding of Israel science foundation (Grant no. 2028/17 and 2209/17) and support of Planning Budgeting Committee/ISRAEL Council for Higher Education (CHE) and Fuel Choice Initiative (Prime Minister Office of ISRAEL), within the framework of Israel National Research Center for Electrochemical Propulsion (INREP). KL was supported by Nanostructures for Electrical Energy Storage (NEES), an Energy Frontier Research Center funded by the U.S. Department of Energy, Office of Science, Office of Basic Energy Sciences under Award Number DESC0001160. Sandia National Laboratories is a multimission laboratory managed and operated by National Technology and Engineering Solutions of Sandia, LLC, a wholly owned subsidiary of Honeywell International, Inc., for the U.S. Department of Energy's National Nuclear Security Administration under contract de-na0003525. This paper describes objective technical results and analysis. Any subjective views or opinions that might be expressed in the paper do not necessarily represent the views of the U.S. Department of Energy or the United States Government.
1 A. Manthiram, K. Chemelewski, and E.-S. Lee. Energy Environ. Sci. 7, 1339 (2014).

2 T.R. Jow, J.L. Allen, O. Borodin, S.A. Delp, and J.L. Allen. TMS 2014 Supp. Proc. 853 (The Minerals, Metals, and Materials Society, 2014).

3 H. Duncan, B. Hai, M. Leskes, C.P. Grey, and G.Y. Chen. Chem. Mater. 26, 5374 (2014).

4 Z. Moorhead-Rosenberg, A. Huq, J.B. Goodenough, and
A. Manthiram. Chem. Mater. 27, 6934 (2015).

${ }^{5} \mathrm{Xu}, \mathrm{K}$. Chem. Rev. 104, 4303 (2014).

6 A. Jarry, S. Gottis, Y.-S. Yu, J. Roque-Rosell, C. Kim, J. Cabana, J. Kerr, and R. Kostecki. J. Am. Chem. Soc. 137, 3533 (2015).

7 X. Fan, L. Chen, O. Borodin, X. Ji, J. Chen, S. Hou, T. Deng, J. Zheng, C. Yang, S.-C. Liou, K. Amine, K. Xu, and C. Wang Nature Nanotech. 13, 715 (2018). 
${ }^{8}$ C.-C. Su, M. He, P.C. Redfern, L.A. Curtiss, I.A. Shkrob, and Z.C. Zhang. Energy Environ. Sci. 10, 900 (2017).

9 M. Hirayama, H. Ido, K.S. Kim, W. Cho, K. Tamura, J. Mizuki, and R. Kanno. J. Am. Chem. Soc. 132, 15268 (2010).

10 M. Hirayama, N. Sonoyama, M. Ito, M. Minoura, D. Mori, A. Yamada, K. Tamura, J. Mizuki, and R. Kanno. J. Electrochem. Soc. 154, A1065 (2007).

11 J.-W. Song, C.C. Nguyen, H. Choi, K.-H. Lee, K.-H. Han, Y.-J. Kim, S. Choy, and S.W. Song, J. Electrochem. Soc. 158, A458 (2011).

12 There are questions about how much $\mathrm{Li}_{2} \mathrm{CO}_{3}$ exists in the CEI. K. Edström, T. Gustafsson, and J.O. Thomas. Electrochem. Acta, 50, 397 (2004).

13 M. Moshkovich, M. Cojocaru, H.E. Gottlieb, and D. Aurbach. J. Electroanal. Chem. 497, 84 (2001).

14 D. Aurbach, B. Markovsky, M.D. Levi, E. Levi, A. Schechter, M. Moshkovich, and Y. Cohen, Y. J. Power Sources 81-82, 95 (1999).

15 T. Yoon, D. Kim, K.H. Park, H. Park, S. Jurng, J. Jang, J.; Ryu, J.H.; Kim, J.J.; Oh, S.M. J. Electrochem. Soc. 161, A519 (2014).

16 T. Yoon, T. Lee, J. Soon, H. Jeong, S. Jurng, J.H. Ryu, and S.M. Oh. J. Electrochem. Soc. 165, A1095 (2018).

17 F. Simmen, A. Hintennach, M. Horisberger, T. Lippert, P. Novák, C.W. Schneider, A. Wokaun. J. Electrochem. Soc. 157, A1026 (2010)

18 S. Fang, D. Jackson, M.L. Dreibelbis, T.F. Kuech, and R.J. Hamers. J. Power Sources, 373, 184 (1028).

19 R. Sahore, F. Dogan, and I.D. Bloom. Chem. Mater. 31, 2884 (2019).

${ }^{20}$ W. Choi and A. Manthiram, J. Electrochem. Soc. 153, A1760 (2006).

21 F. Lin, I.M. Markus, D. Nordlund, T.-C. Weng, M.D. Asta, H.L. Xin, and M.M. Doeff. Nat. Commun. $\mathbf{5}, 3529,(2014)$ and references therein.

${ }^{22}$ L. Zou, Z. Liu, W. Zhao, H. Jia, J. Zheng, Y. Yang, G. Wang, G., J.-L. Zhang, and C.M. Wang. Chem. Mater. 30, 7016 (2018).

23 Y.S. Jung, A.S. Cavanagh, A.C. Dillon, M.D. Groner, S.M. George, and S.-H. Lee. J. Electrochem. Soc. 157, A75 (2010).

24 X.C. Xiao, D. Ahn, Z. Liu, J.-H. Kim, and P. Lu. Electrochem. Commun. 32, 31 (2013).

25 J.W. Kim, D.H. Kim, D.Y. Oh, H. Lee, J.H. Kim, J.H. Lee, and Y.S. Jung. J. Power Sources, 274, 1254 (2015).

26 L. Baggetto, N.J. Dudney, and G.M. Veith. Electrochim. Acta 90, 135 (2013).

27 Y. Kim, N.J. Dudney, M.F. Chi, S.K. Martha, J. Nanda, G.M. Veith and C.D. Liang. J. Electrochem. Soc. 160, A3113 (2013).

28 X. Wang, and G. Yushin. Energy Environ. Sci. 8, 1889 (2015).

29 J. Alvarado, M.A. Schroeder, M. Zhang, O. Borodin, E. Gobrogge, M. Olguin, M.S. Ding, M. Gobet, S. Greenbaum, Y.S. Meng, and K. Xu. Materials Today 21, 341 (2018).

30 M. Matsui, K. Dokko, and K. Kanamura. J. Electrochem. Soc. 157, A121 (2010).

31 C.-Y. Tang, K. Leung, R.T. Haasch, and S.J. Dillon. ACS Appl. Mater. Interfaces 9, 33968 (2017).

32 C.Y. Tang, Y. Ma, R.T. Haasch, J.-H. Ouyang, and
S.J. Dillon. J. Phys. Chem. Lett. 8, 6226 (2017).

33 Z.W. Lebens-Higgins, S. Sallis, N.V. Faenza, F. Badway, N. Pereira, D.M. Halat, M. Wahila, C. Schlueter, T.-L. Lee, W. Yang, C.P. Grey, G.G. Amatucci, and L.F.J. Piper. Chem. Mater. 30, 958 (2018).

34 H.-J. Peng. Ph.D Thesis, https://doi.org/10.3929/ethz-a010793448

35 Y. Ma, L .Feng, C.-Y. Tang, J.-H. Ouyang, and S.J. Dillon. J. Electrochem. Soc. 165, A3084 (2018).

36 Z. Zhou, P. Lu, C. Delacourt, R. Qiao, K. Xu, F. Pan, S.J. Harris. Chem. Commun. 54, 814 (2018).

37 G.M. Veith, M. Doucet, J.K. Baldwin, R.L. Sacci, T.M. Fears, Y. Wang, and J.F. Browning. J. Phys. Chem. C, 119, 20339 (2015).

38 K. Leung, F. Soto, K. Hankins, P.B. Balbuena, and K.L. Harrison. J. Phys. Chem. C, 120, 6302 (2016).

39 F. Soto, Y. Ma, J. Martinez de la Hoz, J. Seminario, P.B. Balbuena. Chem. Mater. 27, 7990 (2015).

40 F.L. Zhang, T.T. Geng, F.F. Peng, D.N. Zhao, N.S. Zhang, H.M. Zhang, and S.Y. Li. ChemElectroChem 6, 731 (2019).

41 D.N. Zhao, S.N. Song, X.S. Ye, P. Wang, J. Wang, Y. Wei, C.L. Li, L.P. Mao, H.M. Zhang, and S.Y. Li. Appl. Sur. Sci. 491, 595 (2019).

${ }^{42}$ M. He, L. Boulet-Roblin, P. Borel, C. Tessier, P. Novák, C. Villevielle, and E.J. Berg. J. Electrochem. Soc. 163, A83 (2016).

43 R. Jung, P. Strobl, F. Maglia, C. Stinner, and H.A. Gasteiger, H.A. J. Electrochem. Soc. 165, A2869 (2018).

44 R. Jung, M. Metzger, F. Maglia, C. Stinnner, and Gasteiger, H.A. J. Phys. Chem. Lett. 8, 4820 (2017).

45 M. Metzger, C. Marino, J. Sicklinger, D. Haering, and H.A. Gasteiger. J. Electrochem. Soc. 162, A1123 (2015).

${ }^{46} \mathrm{M}$. Xu, N. Tsiouvaras, A. Garsuch, H.A. Gasteiger, and B.L. Lucht. J. Phys. Chem. C 118, 7363 (2014).

47 H. Wang, E. Rus, T. Sakuraba, J. Kiluchi, Y. Kiya, H.D. Abruna. Anal. Chem. 86, 6197 (2014).

48 B. Michalak, B.B. Berkes, H. Sommer, T. Bergfeldt, T. Brezesinski, and J. Janek. Anal. Chem. 88, 2877 (2016).

49 Z. Jusys, M. Binder, J. Schnaidt, and R.J. Behm. Electrochim. Acta 314, 188 (2019).

50 L. Xing, O. Borodin, G.D. Smith, and W. Li. J. Phys. Chem. A 115, 13896 (2011).

51 O. Borodin, X. Ren, J. Vatamanu, A.v.W. Cresce, J. Knap, and K. Xu. Acc. Chem. Res. 50, 2886 (2017).

${ }^{52}$ Y. Okuno, K. Ushirogata, K. Sodeyama, G. Shukri, and T. Tateyama. J. Phys. Chem. C 123, 2267 (2019).

53 K. Leung. J. Phys. Chem. C 116, 9852 (2012).

54 M. Kumar, K. Leung, D.J. Siegel. J. Electrochem. Soc. 161, E3059 (2014).

55 O. Borodin, M. Olguin, C.E. Spear, K.W. Leiter, J. Knap. Nanotechnology 26, 354003 (2015).

56 L. Giordano, P. Karayaylali, Y. Yu, F. Maglia, S. Lux, and Y. Shao-Horn. J. Phys. Chem. Lett. 8, 3881 (2017).

57 T.M. Ostergaard, L. Giordano, I.E. Castelli, F. Maglia, B.K. Antonopoulos, Y. Shao-Horn, and J. Rossmeisl. J. Phys. Chem. C 122, 10442. (2018).

58 J.L. Tebbe, T.F. Fuerst, C.B. Musgrave. ACS Appl. Mater. Interfaces 8, 26664 (2016).

59 J.L. Tebbe, T.F. Fuerst, and C.B. Musgrave, C.B. J. Power Soures 297, 427 (2015). 
${ }^{60}$ S. Xu, G. Luo, R. Jacobs, S. Fang, M.K. Mahanthappa, R.J. Hamers, and D. Morgan. ACS Appl. Mater. Interfaces 9, 20545 (2017).

61 L. Huai, Z. Chen, and L. Li. ACS Appl. Mater. Interfaces 9, 36377 (2017).

62 X. Qin, P.B. Balbuena, M. Shao. J. Phys. Chem. C 123, 14449 (2019).

63 E. Evenstein, Rosy, S. Haber, H. Sclar, L. Houlen, K. Leung, M. Leskes, and M. Noked. Energy Storage Mater. 19, 261 (2019).

64 N.N. Intan, K. Klyukin, V. Alexandrov. ACS Appl. Mater. Interfaces 11, 20110 (2019).

65 R. Benedek. J. Phys. Chem. C 121, 22049 (2017).

66 Such CEI formation behavior would be distinct from lithium ion battery anodes where parasitic reactions responsible for formation and evolution of solid-electrolyteinterphase surface films often involve long-range electron transfer, and can occur away from electrode surfaces.

67 C. Adamo and V. Barone. J. Chem. Phys. 110, 6158 (1999).

68 G. Tian, Y. Mo, J. Tao. Computation 5, 27 (2017).

69 A.J. Cohen, P. Mori-Sanchez, W.T. Yang. Science 321, 792 (2008).

70 S.L. Dudarev, G.A. Botton, S.Y. Savrasov, C.J. Humphreys, and A.P. Sutton. Phys. Rev. B 57, 1505 (1998).

71 S.E. Renfrew and B.D. McCloskey. J. Am. Chem. Soc. 139, 17853 (2017).

72 N. Mahne, S.E. Renfrew, B.D. McCloskey, S.A. Freunberger. Angew. Chem. Int. Ed. 57, 5529 (2018).

73 A.C. Luntz, and B.D. McCloskey. Chem. Rev. 114, 11721 (2014).

74 S. Meini, N. Tsiouvaras, K.U. Schwenke, M. Piana, H. Beyer, L. Lange, and H.A. Gasteiger Phys. Chem. Chem. Phys. 15, 11478 (2013).

75 G. Kresse, and J. Furthmüller. Phys. Rev. B 54, 11169 (1996).

76 G. Kresse and J. Furthmüller. Comput. Mater. Sci. 6, 15 (1996).

77 G. Kresse and D. Joubert. Phys. Rev. B 59, 1758 (1999).

78 J. Paier, M. Marsman, and G. Kresse. J. Chem. Phys. 127, 024103 (2007).

79 J.P. Perdew, K. Burke, and M. Ernzerhof. Phys. Rev. Lett. 77, 3865 (1996).

80 F. Zhou, M. Cococcioni, C.A. Marianetti, D. Morgan, and G. Ceder. Phys. Rev. B 70, 235121 (2004).

81 J.-H. Kim, A. Huq, M.F. Chi, N.P.W. Pieczonka, E. Lee, C.A. Bridges, M.M. Tessema, A. Manthiram, K.A. Persson, and B.R. Powell. Chem. Mater. 26, 4377 (2014).
82 Other DFT $+\mathrm{U}$ implementations have been applied to spinel LMO; see I. Scivetti and G. Teobaldi. J. Phys. Chem. C 119, 21358 (2015).

83 M.S. Islam and C.A.J. Fisher, C.A.J. Chem. Soc. Rev. 43, 185 (2014).

84 J. Neugebauer and M. Scheffler. Phys. Rev. B 46, 16067 (1992).

85 G. Henkelman, B.P. Uberuaga, and H. Jonsson. J. Chem. Phys. 113, 9901 (2000).

86 The (111) surface should be most prominent, and reconstructed (111) surface models have been devised. ${ }^{81,87,88}$ Direct contact betweeh molecules and transition metal ions on the (111) surface will first require creation of oxygen vacancies. The (001) surface, which requires a smaller simulation cell and is commensurate with $\mathrm{Li}_{2} \mathrm{CO}_{3}$ lattice constants, is adopted herein for ease of computation.

87 E. Lee, K.A. Persson. Chem. Mater. 25, 2885 (2013).

88 N.N. Intan, K. Klyukin, V. Alexandrov. J. Electrochem. Soc. 165, A1099 (2018).

89 N. Marzari and D. Vanderbilt. Phys. Rev. B, 56, 12847 (1997).

90 D. Aurbach, K. Gamolsky, B. Markovsky, G. Salitra, Y. Gofer, U. Heider, R. Oesten, and M. Schmidt, M. J. Electrochem. Soc. 147, 1322 (2000).

91 K. Leung and A. Leenheer. J. Phys. Chem. C 119, 10234 (2015).

92 Y. Duan and D.C. Sorescu. Phys. Rev. B 79, 014301 (2009).

93 S. Shi, Y. Qi, H. Li, and L.G. Hector. J. Phys. Chem. C 117, 8579 (2013).

94 The potential should technically also depends on the outer interface between $\mathrm{Li}_{2} \mathrm{CO}_{3}$ and the polymeric CEI on top of it, as well as the polymeric CEI/liquid electrolyte interface. The structures of these highly complex interfaces are unknown, and they are neglected herein.

95 S. Trasatti. Pure Appl. Chem. 58, 955 (1986).

96 K. Leung. Phys. Chem. Chem. Phys. 17, 1637 (2015).

97 M.-T. F. Rodrigues, K. Kalaga, S.E. Trask, I.A. Shkrob, D.P. Abraham. J. Electrochem. Soc. 165, A1697 (2018).

98 M. Metzger, B. Strehle, S. Solchenbach, and H.A. Gasteiger. J. Electrochem. Soc. 163, A1219 (2016).

99 S. Kasamatsu and O. Sugino. J. Phys. Condens. Mat. 31, 085901 (2019).

100 D. Qian, Y. Hinuma, H. Chen, L.-S. Du, K.J. Carroll, G. Ceder, C.P. Grey, and Y.S. Meng. J. Am. Chem. Soc. 134, 6096 (2012). 